\title{
Assessment of co-seismic landslide susceptibility using LR and ANCOVA in Barpak region, Nepal
}

\author{
Suchita Shrestha, Tae-Seob Kang and Jung Chang Choi* (i) \\ Department of Earth and Environmental Sciences, Pukyong National University, 45 Yongso-ro, Nam-gu, \\ Busan 48513, Republic of Korea. \\ *Corresponding author. e-mail: jcchoi@pknu.ac.kr
}

MS received 22 June 2017; revised 31 August 2017; accepted 8 September 2017; published online 28 March 2018

Nepal was affected by a catastrophic earthquake with Mw 7.8 on 25th April, 2015 with its epicenter in the central part of Barpak village. A number of co-seismic landslides were triggered by the main shock of the event and associated aftershocks. Due to the rugged topography and vicinity of the main shock, the village was extremely affected by co-seismic landslides. In total, 59 landslides were identified using Google Earth and were verified during the field survey in Barpak village. Furthermore, 11 conditioning factors, including Peak ground acceleration (PGA), epicenter proximity, fault proximity, geology, slope, elevation, plan curvature, profile curvature, topographic wetness index, drainage proximity and the sediment transport index were selected as independent variables for analysis. In this study, logistic regression (LR) and analysis of covariance (ANCOVA) models were used and their performance was assessed. Finally, the landslide susceptibility classes were produced and an evaluation of models was done by using receiver operating characteristic curves. The area under the curve for LR and ANCOVA showed 85.38 and 78.4\% accuracy, respectively. Based on the overall assessments, the LR model was more accurate than the ANCOVA model for co-seismic landslide prediction in the study area. The result of this study can be used to mitigate landslide-induced hazards and for land-use planning.

Keywords. Analysis of covariance; co-seismic landslide; GIS; logistic regression; landslide susceptibility.

\section{Introduction}

Nepal is one of the most earthquake-prone countries in the world because it is located at the junction between the Indian plate and Tibetan plate (Dewey and Burke 1973). At 11:56:26 local time on 25th of April 2015, a catastrophic earthquake with Mw 7.8 (USGS) struck Nepal (National Seismological Center, Government of Nepal has declared the magnitude as 7.6). According to Ministry of Home Affairs (MoHA) 2015, as a result of the earthquake, 8962 people were killed and thousands became homeless. Thousands of houses were destroyed across many districts of the country, with entire villages flattened, especially those near the epicenter. According to Keefer (1994), earthquakes can trigger different types of secondary natural hazards; among them co-seismic landslides are the most common. Gorkha earthquake was no exception. The earthquake also triggered various mass movements (Kargel et al. 2016; Regmi et al. 2016).

Globally, co-seismic landslides have attracted a lot of attention among scientists because the shaking initiated by the earthquake might weaken the slope, such as when a new earthquake or rainfall can fail the hill slope. Different methods related 
to co-seismic landslides have been developed for assessing the hazard. Two significant methods have been identified for the assessment of the probability of occurrence of co-seismic landslides, such as the deterministic and statistical methods. The deterministic approach is often referred to as the sliding block method (Newmark 1965; Sarma 1975; Bray et al. 1998), which provides slope stability based on stress change due to seismic acceleration (Yegian et al. 1991). Another deterministic approach uses the finite element model, which estimates strain potential and is based on stress-deformation analysis (Seed et al. 1973). Different types of statistical approaches have also been proposed for co-seismic landslide susceptibility (Jibson et al. 2000; Miles and Keefer 2000; Lee et al. 2008). Basically, statistical models incorporate conditioning factors $(\mathrm{CF})$ such as slope, elevation, and drainage proximity with peak ground acceleration (PGA) as the triggering factor (Miles and Keefer 2007, 2009a, b). Only a few researchers used geotechnical data as the $\mathrm{CF}$ because extensive geotechnical data are not available for regional-scale assessment of co-seismic landslide susceptibility analysis (Wasowski et al. 2011).

Our study describes the performances of two statistical methods, namely Logistic Regression (LR) and Analysis of Covariance (ANCOVA), for evaluating rapid co-seismic landslide susceptibility. The LR method has been applied by various researchers (Jade and Sarkar 1993; Dai et al. 2001; Devkota et al. 2013). An ANCOVA is a normal linear model that combines analysis of variance and regression with qualitative and continuous covariates. Both methods are easy to use and do not need to be classified in different intervals. Whereas, many bivariate models need that the independent variables be classified (Chung and Fabbri 1999; Bednarik et al. 2010). This study also shows the accuracy of nonlinear (LR) and linear (ANCOVA) models.

\section{Study area}

Barpak village lies in the central part of the Gorkha district of Nepal (figure 1). Since this village lies close to the epicenter of the Gorkha earthquake and is also embedded in a steep hill, it was intensely affected by the earthquake. According to the report, at the time of the Gorkha earthquake, less than 10 out of 1200 houses remained standing (MoHA 2015). Barpak village covers $90.06 \mathrm{~km}^{2}$ area and the elevation ranged from 824.8 to 5439.6 above mean sea level. The study area lies on the Higher Himalaya and Lesser Himalaya zones (Sharma 1990). These two geological zones occupy 44.1 and $56.9 \%$ area of Barpak village, respectively.

The epicenter of the main shock was located in Barpak, Gorkha, at latitude $28^{\circ} 15^{\prime} 07^{\prime \prime} \mathrm{N}$, and longitude $84^{\circ} 07^{\prime} 02^{\prime \prime} \mathrm{E}$, approximately $75 \mathrm{~km} \mathrm{NW}$ of

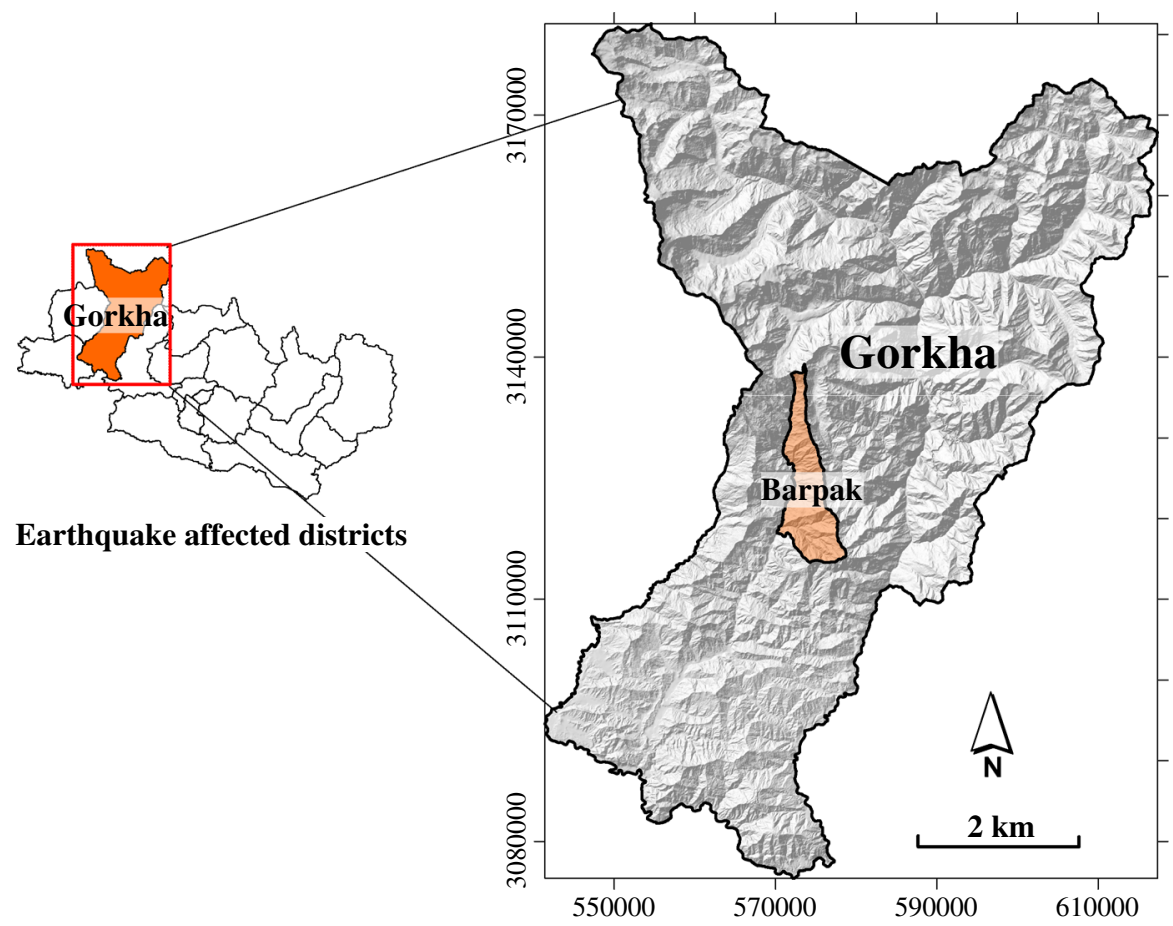

Figure 1. Location map of the study area. 

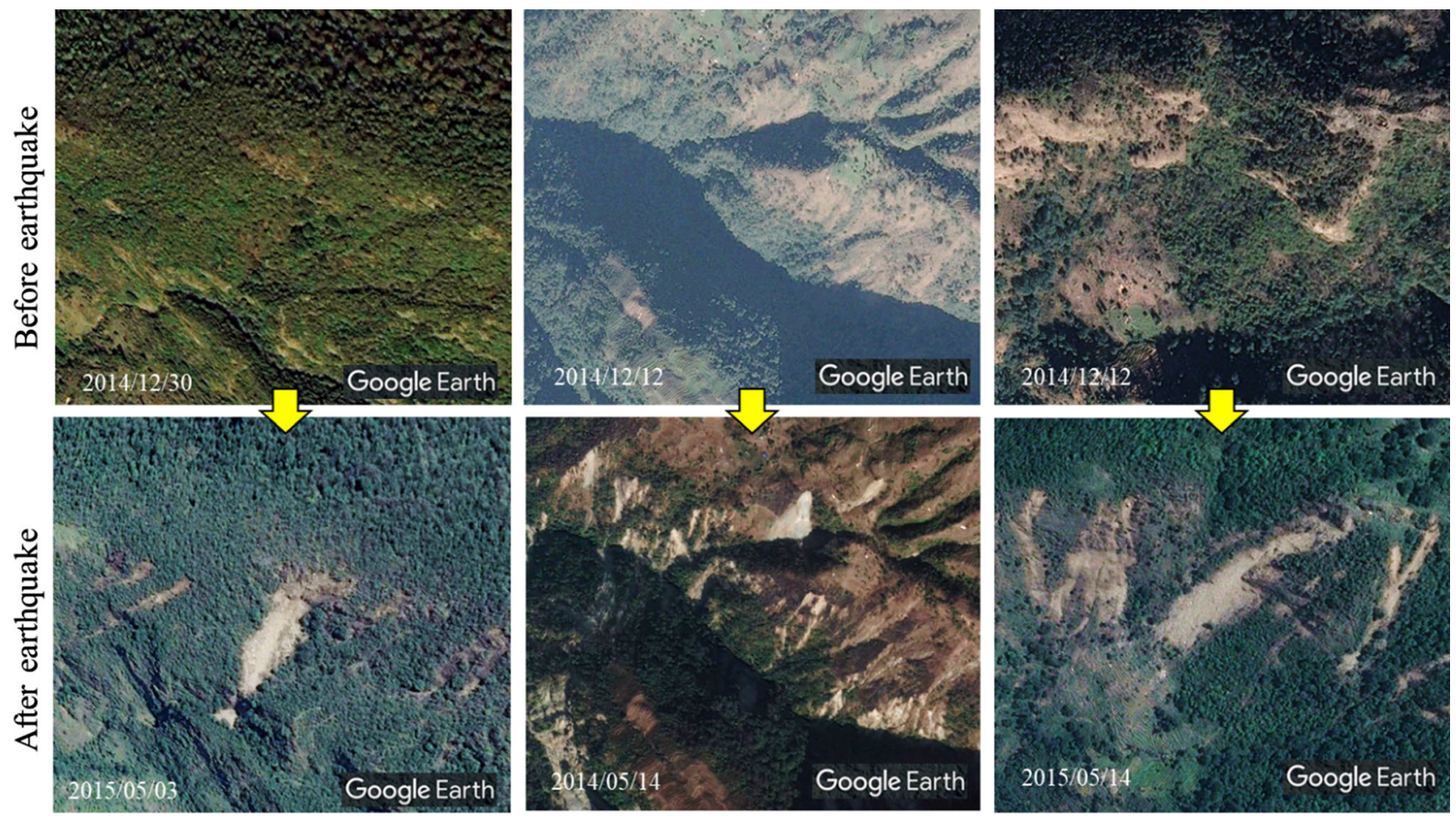

Figure 2. Google earth image before and after the Gorkha earthquake.
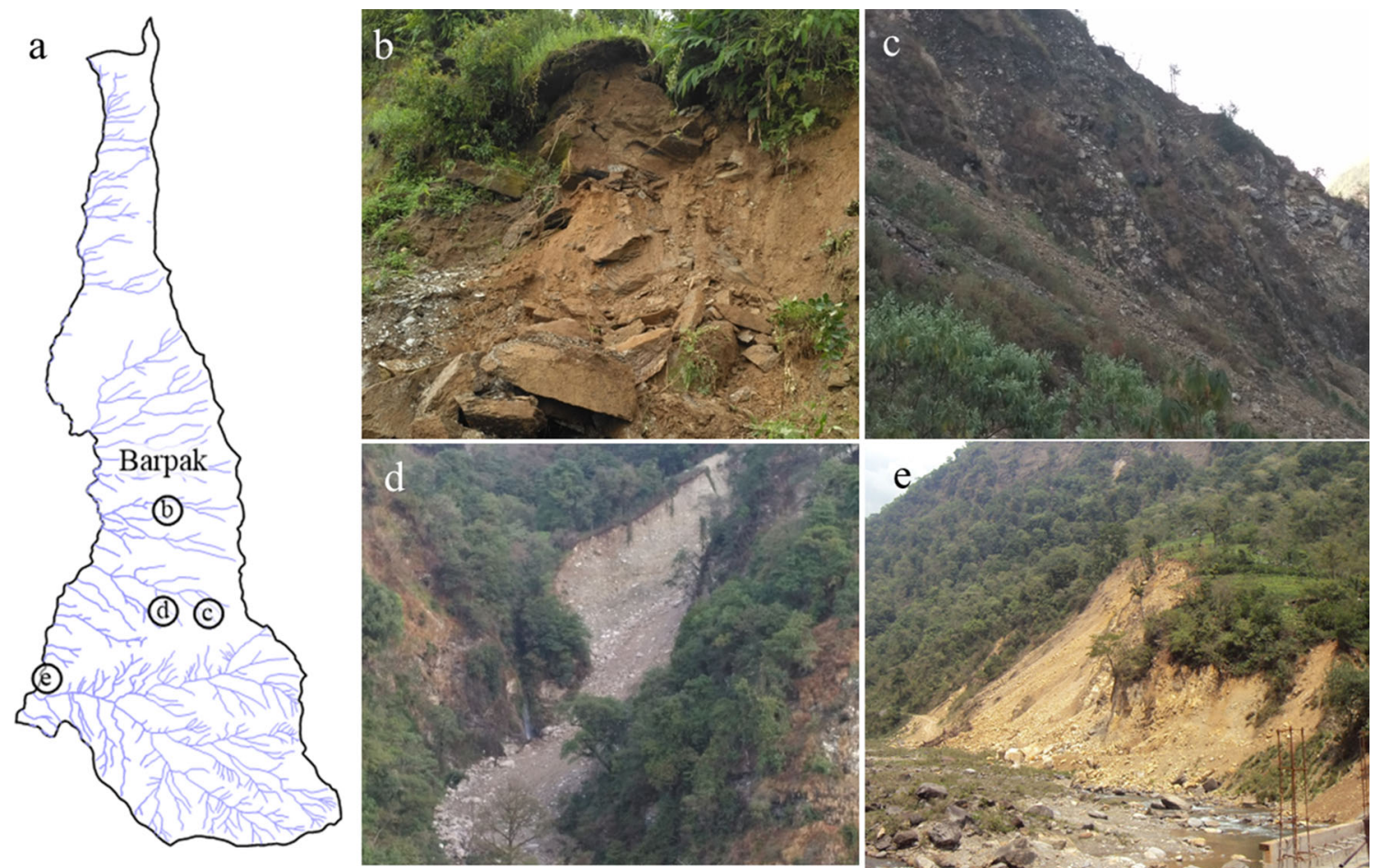

Figure 3. (a) Photo index; (b) rock topple; (c) slope fall; (d) debris flow; and (e) shallow landslide.

Kathmandu. Due to the vicinity of the epicenter, the study area has been affected by the seismically induced mass movements. The landslide inventory was prepared by a remote Google Earth-aided recognition survey. The images of pre-earthquake, and post-earthquake events were analyzed using the Google Earth historical archive tool (figure 2). A field survey was also carried out to perform a field check on randomly selected affected sites of the study area. During the earthquake, the short-lived strong ground motion produced several slope failures (figure 3). Altogether, 59 landslides 


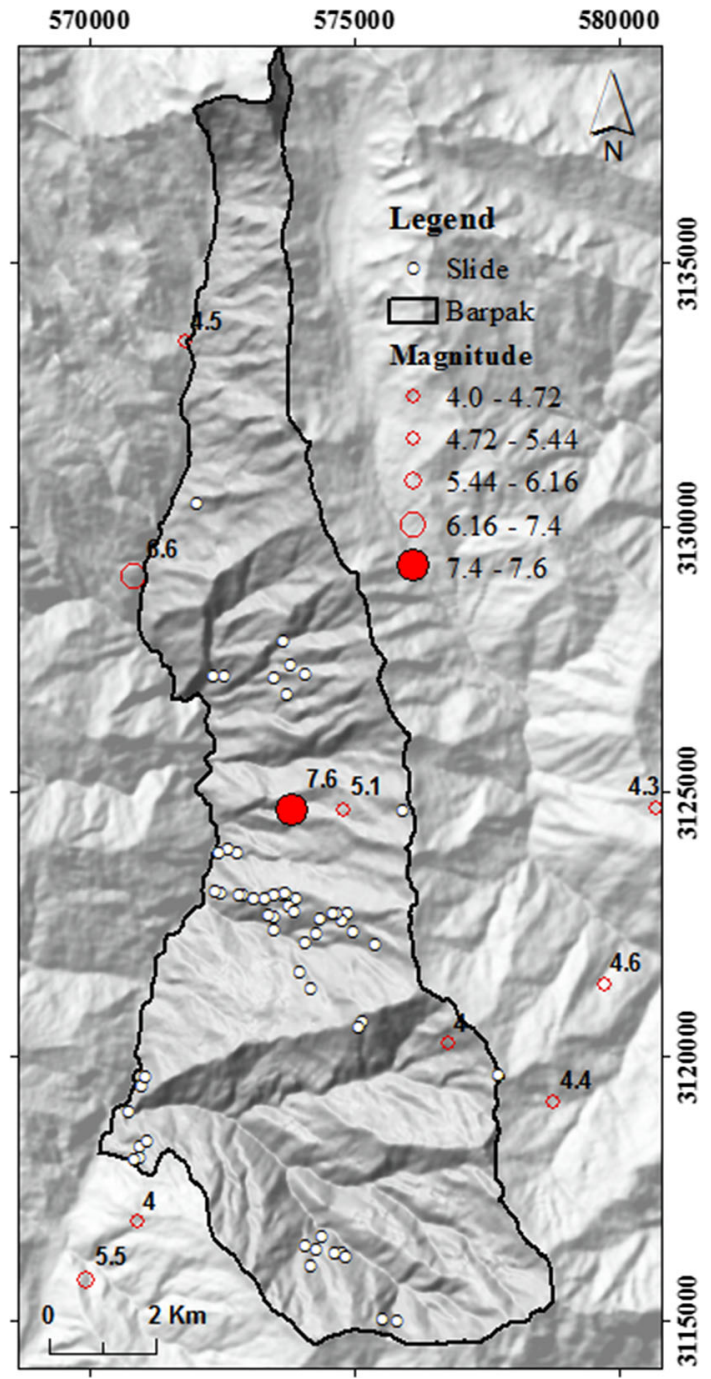

Figure 4. Landslide inventory and epicenter map.

were correctly identified and digitized in a GIS environment, as shown in figure 4. Most of the observed landslides are rock failure, however, in this study, the landslides were considered altogether (deep seated, shallow, rock fall, debris flow) in order to know the probability associated with the earthquake event.

\section{Landslide-influencing factors and landslide distribution}

The factors that affect landslides are very complex. The landslide-inducing factors considered in this study were collected based on two key attributes: relevance and availability. Here, relevance refers to the main CFs of a landslide in the study area, and availability refers to whether the relevant factor data can be readily obtained for use in developing a landslide susceptibility map. In this study, 11 most frequently used factors were used for landslide susceptibility modeling, these are peak ground acceleration (PGA; Weng et al. 2011; Saputra et al. 2016); epicenter proximity (Delgado et al. 2011; Regmi et al. 2016); fault proximity (Kamp et al. 2008; Kritikos et al. 2015; Wang et al. 2015); geology (Lee and Evangelista 2006; Lee et al. 2008; Zhou et al. 2016); slope and elevation (Kamp et al. 2008; Pradhan and Lee 2010; Regmi et al. 2010; Wang et al. 2015; Regmi et al. 2016); plan curvature (Kamp et al. 2008); profile curvature (Weng et al. 2011), topographic wetness index (TWI; Pradhan and Lee 2010; Pradhan and Kim 2016); drainage proximity (Kamp et al. 2008) and sediment transport index (STI; Regmi et al. 2010; Pradhan and Kim 2016). The spatial distribution of landslides in each independent variable was analyzed using GIS. Among the above-mentioned CFs, geology is categorical variable and the remaining are numerical variables.

\subsection{Seismic and geologic parameters}

PGA is a triggering factor and is associated with seismic intensity. In general, co-seismic landslides increase with PGA values (Liao and Lee 2000). The PGA attribute of the study area was extracted from the PGA map related to the Gorkha earthquake (USGS 2015), which was released by the US Geological Survey (USGS, www.usgs.gov) as shown in figure 5(a). From the spatial distribution analysis of the landslide, it shows a very good correlation with PGA. It can be seen that the landslide was mainly distributed, where the PGA is high (figure $5 \mathrm{~b}$ ). In comparison with the felt earthquake intensity, 0.6 and a higher PGA indicate violent to extreme shaking. This can thus generate a large number of co-seismic landslides in steep mountain slopes (Regmi et al. 2016).

The epicenter distance is also one of the important factors (Delgado et al. 2011). The intensity of an earthquake decreases as the distance from the epicenter increases (Regmi et al. 2016).

In this study, 24 aftershocks exceeding magnitudes greater than $4 \mathrm{Mw}$ in the Gorkha district were selected to prepare an epicenter proximity map as shown in figure 6(a). The frequency distribution analysis shows that landslides are mostly concentrated in the vicinity of the epicenters. In this case, 47 landslides were situated within a $5 \mathrm{~km}$ distance from the epicenters (figure $6 \mathrm{~b}$ ).

Co-seismic landslides were strongly controlled by faults (Harp et al. 2003). In this study, faults were 


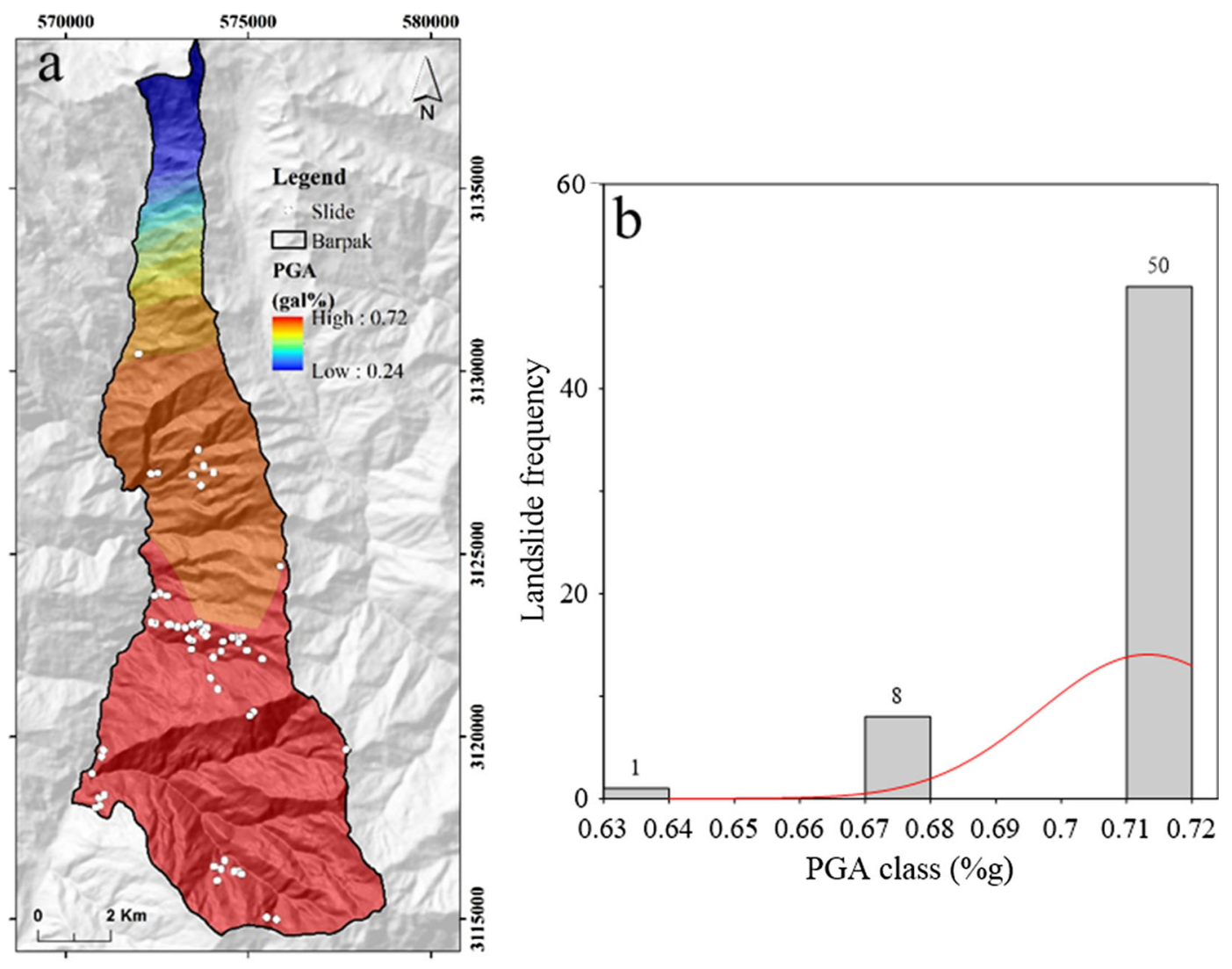

Figure 5. (a) PGA and (b) landslide distribution.

derived from the geological map prepared by the Department of Mines and Geology, Government of Nepal. Then, faults were buffered to create a fault proximity map (figure 7a). The frequency analysis shows that most of the landslides are concentrated within $1 \mathrm{~km}$ from the thrust and faults (figure $7 \mathrm{~b}$ ).

The geological map was obtained from the Department of Mines and Geology, Government of Nepal. The study area lies in the Higher Himalayan Crystalline and Lesser Himalaya zones. These two groups are divided by the Main Central Thurst (MCT). The Higher Himalayan Crystalline zone consists of garnet biotite gneisses, kyanite biotite gneisses, garnetiferous mica schist, augen gneisses, micaceous quartzites and thin bands of marbles. In the study area, the Lesser Himalaya zone consists of Ghanapokhara Formation (Gp), comprising of carbonates, white to gray compact dolomite and dolomitic limestones interbedded with shale beds. Black to gray carbonaceous slates and green shales were also identified ( $\mathrm{Cr}$ ) as a member of $\mathrm{Gp}$, as shown in figure 8(a). From the correlation analysis, it is depicted that the Gp Formation has the highest frequency distribution of landslides (figure $8 \mathrm{~b}$ ). Most of this formation contains highly fractured and jointed rocks that were affected by the quake.

\subsection{Topographic parameters}

The digital elevation model (DEM) has been used as a vital factor in several co-seismic landslide studies (Kamp et al. 2008; Wang et al. 2015). A DEM of $30 \times 30 \mathrm{~m}$ was prepared using a digital contour with $20 \mathrm{~m}$ intervals and the topographic factors such as slope, plan curvature and profile curvature were derived from the DEM. Although there is no direct relationship between elevation and landslide occurrence, research has shown an increase in landslide occurrence at higher elevations (Ercanoglu et al. 2004). Elevation in the study area ranged from 824.8 to 5439.6 MSL as presented in figure 9(a). In the case of elevation, most of the landslides that were concentrated in the elevation ranged from 1800 to 2000 MSL (figure 9b), because most of the aftershocks were concentrated within this altitude.

The terrain slope calculates the slope at any pixel on the surface. From the definition of the gradient, the slope was derived from the first derivative function of the DEM. In the study area, the slope angle ranges from 0 to $72^{\circ}$ as shown 

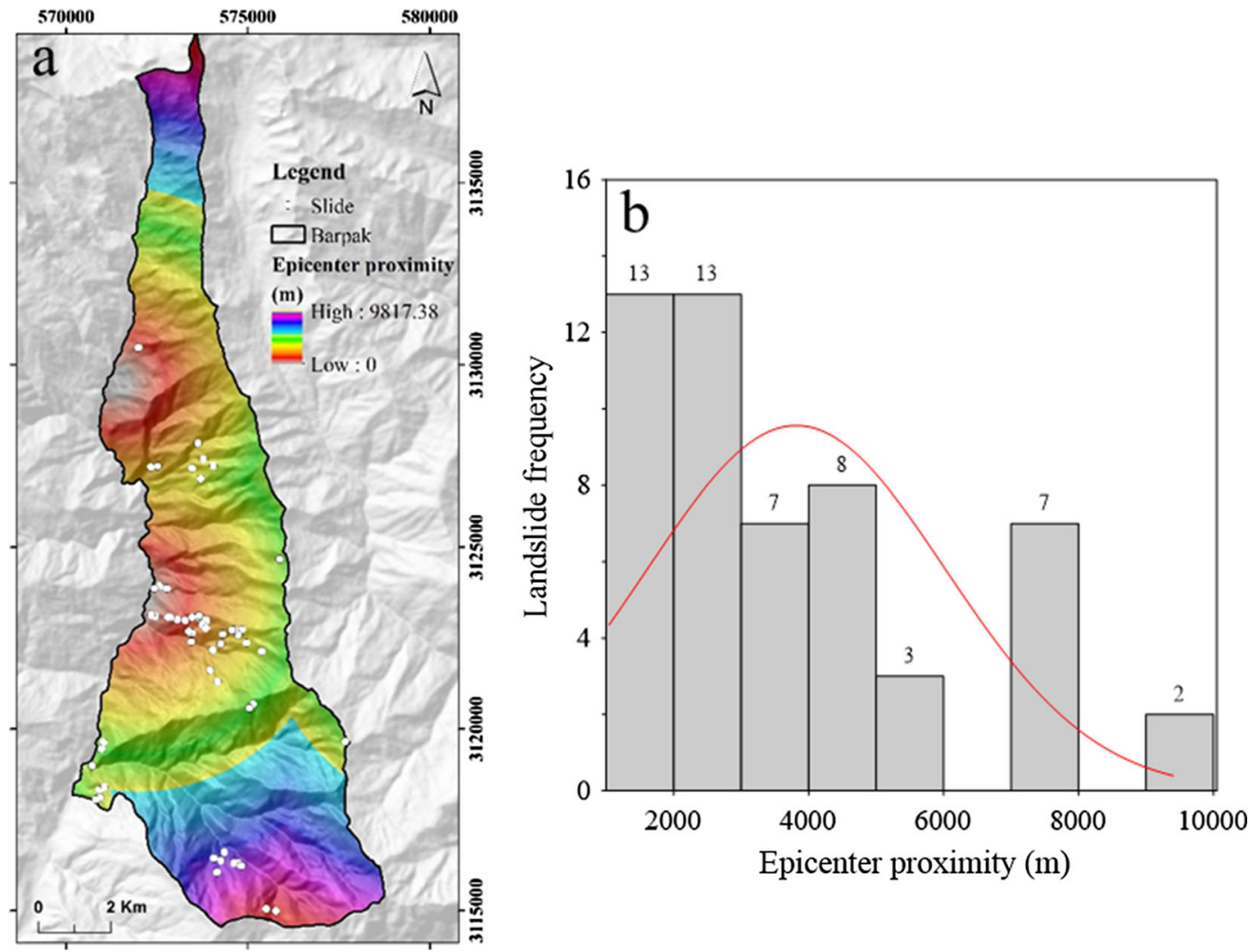

Figure 6. (a) Epicenter proximity and (b) landslide distribution.
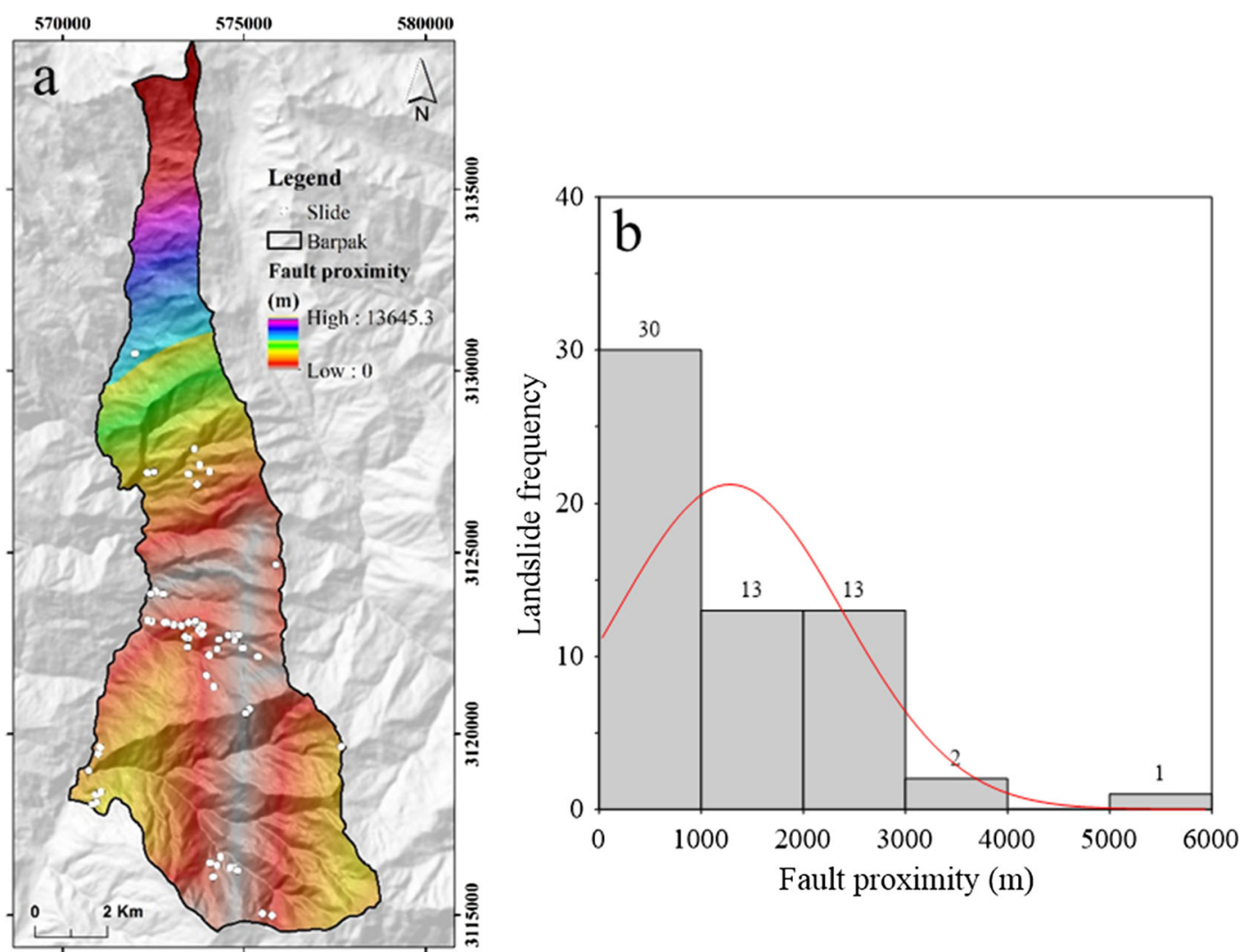

Figure 7. (a) Fault proximity and (b) landslide distribution. 


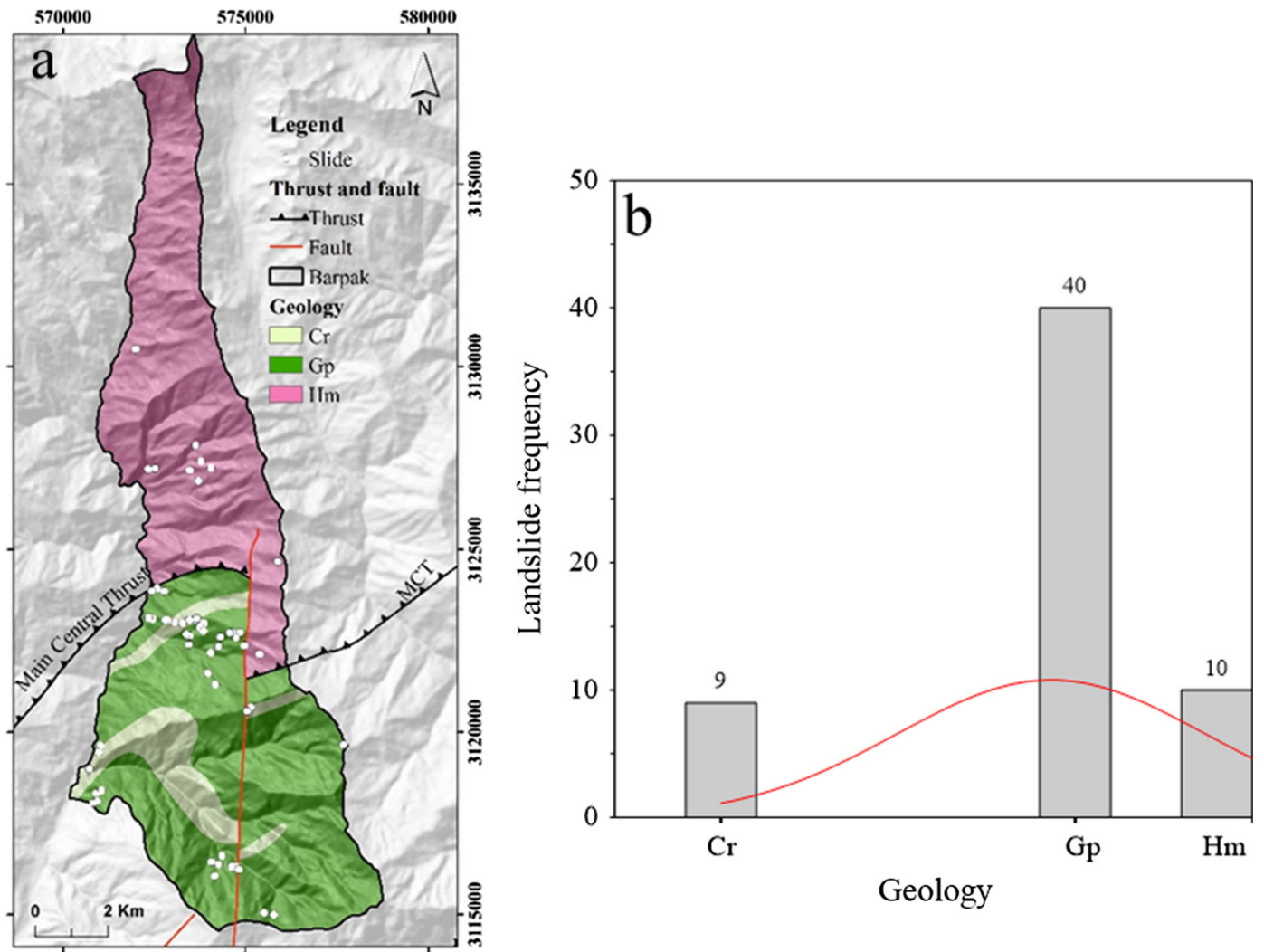

Figure 8. (a) Geology and (b) landslide distribution.

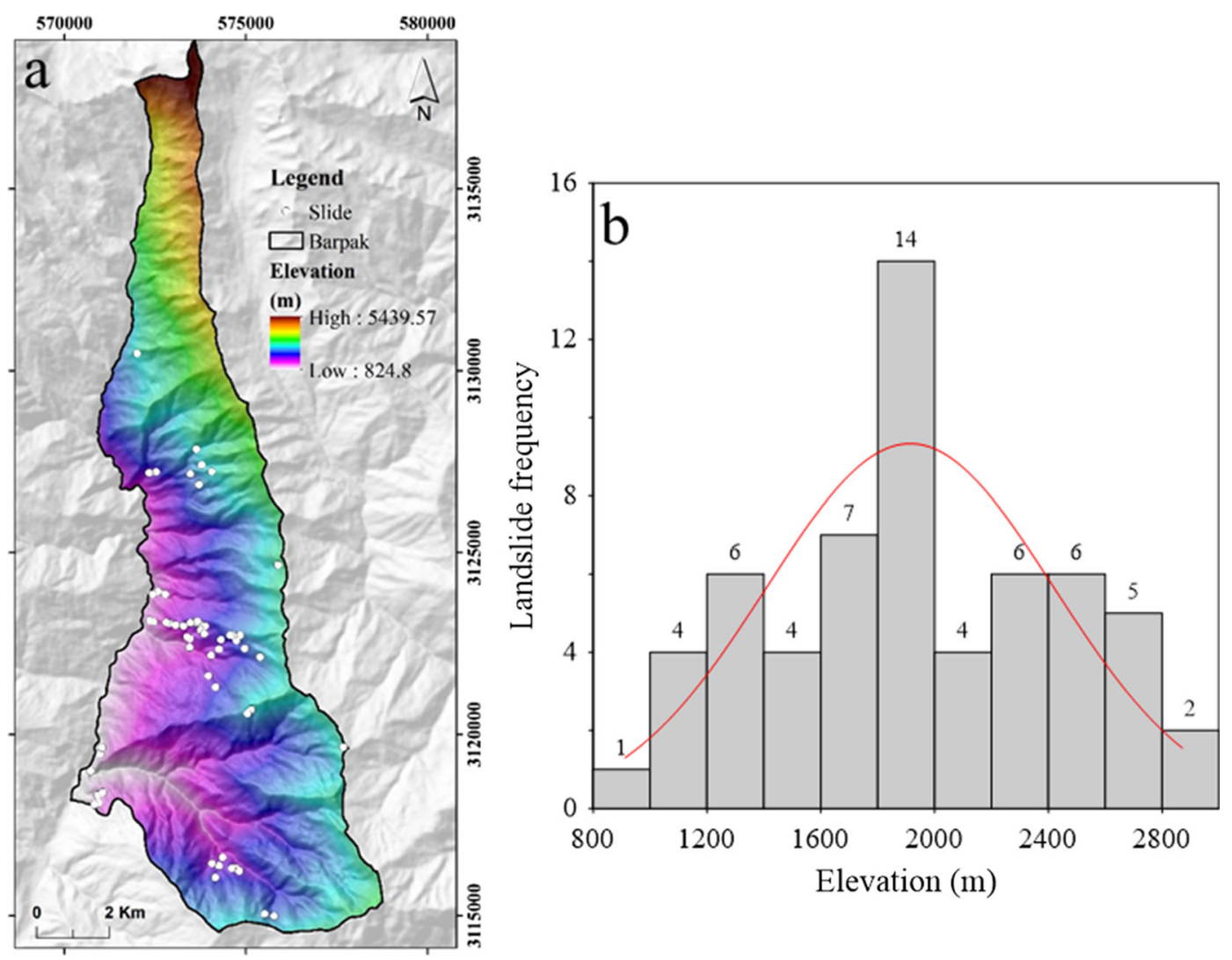

Figure 9. (a) Elevation and (b) landslide distribution. 


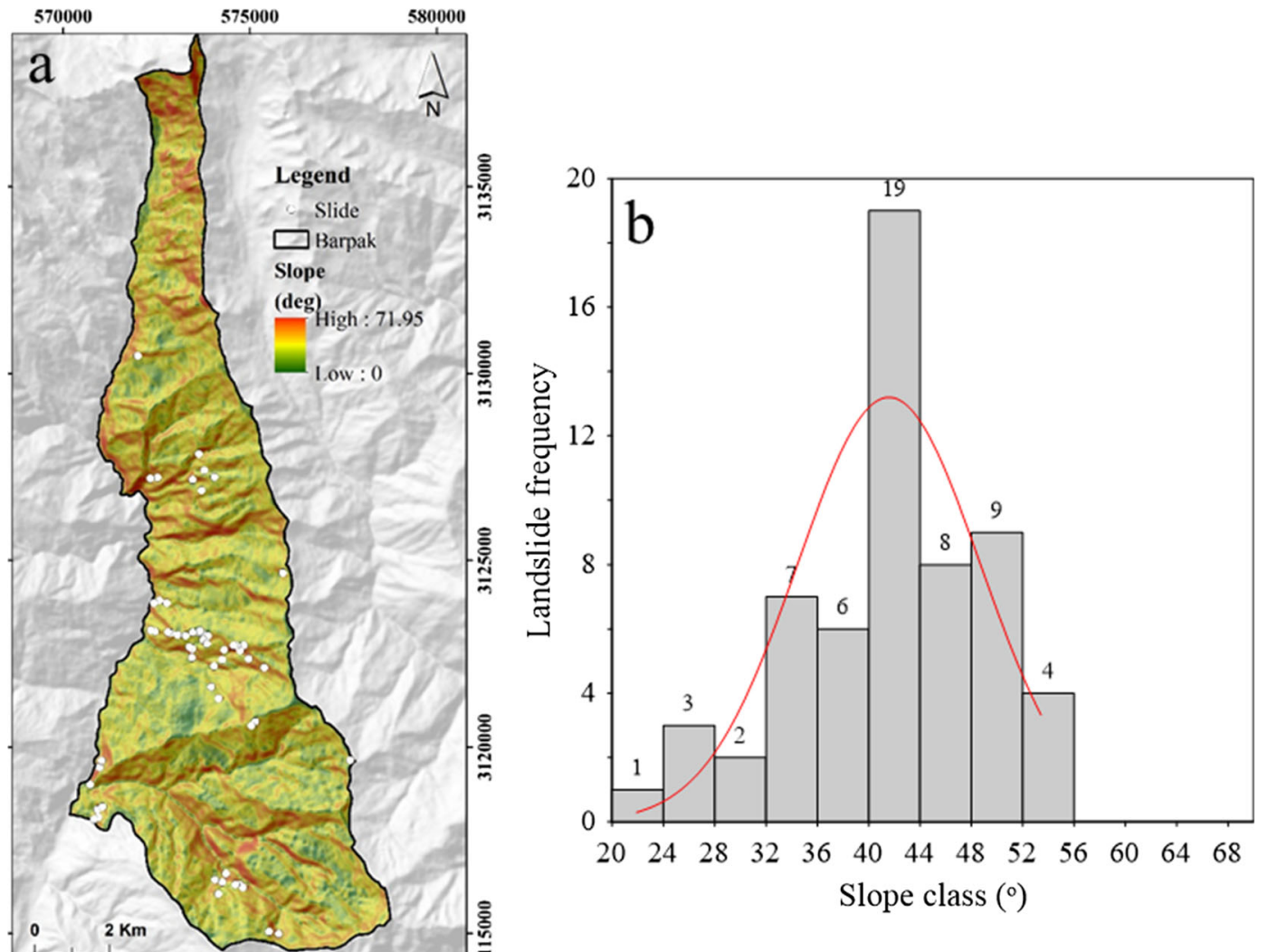

Figure 10. (a) Slope and (b) landslide distribution.

in figure 10(a). The distribution of landslides was mostly concentrated along the slope from 36 to $52^{\circ}$ (figure 10b), because colluvium deposits are resting on these slopes and they became unstable during the shocks; also, the terrain slope above $52^{\circ}$ shows a low frequency of landslides as neither colluvium nor weathered soil can stand on these slopes (Magliulo et al. 2008).

The slope shape can act as a concentrated or scattering surface; it has a strong influence on slope instability, and is the second derivative of the DEM. It is the main determinant of groundwater in the terrain. The DEM using the SAGA GIS ver3.0 (www.saga-gis.org) were used to extract the Plan curvature (figure 11a) and profile curvature (figure $11 \mathrm{~b})$. In both of the curvatures, the landslides are mostly distributed in the planar and concave slopes (figure 11c and d). In the planar and concave surfaces, water can converge as it moves down the slope in such areas (Reneau and Dietrich 1987).

\subsection{Hydrologic parameters}

Drainage proximity, TWI and STI are hydrologic factors, which play vital roles in slope instability (Gökceoglu and Aksoy 1996; Pradhan and Kim
2015). During the shaking, saturated or partially saturated soil slope loses its strength, causing it to behave like a liquid. The Euclidean function in GIS (Regmi et al. 2010; Wang et al. 2015) was used to calculate the drainage proximity (figure 12a). The landslide frequency is higher in the proximity of drainage (figure 12b). The river valleys have created steep slopes in its vicinity and water can adversely affect the slope by cutting the toe of terrain.

The TWI (figure 13a) explains the influence of topography on the position and size of saturated regions of runoff generation. It generally shows the spatial distribution of soil moisture (Beven and Kirkby 1979). Moore et al. (1991) proposed equation (1) for the calculation of TWI under the assumption of steady-state conditions and uniform soil properties

$$
\mathrm{TWI}=\log \left(\frac{\alpha}{\tan \beta}\right),
$$

where $\alpha$ is the cumulative upslope area draining through a point (per unit contour length), and $\tan \beta$ is the slope angle at that point.

The landslide frequency is higher in lower TWI values (figure 13b), because lower TWI values are 


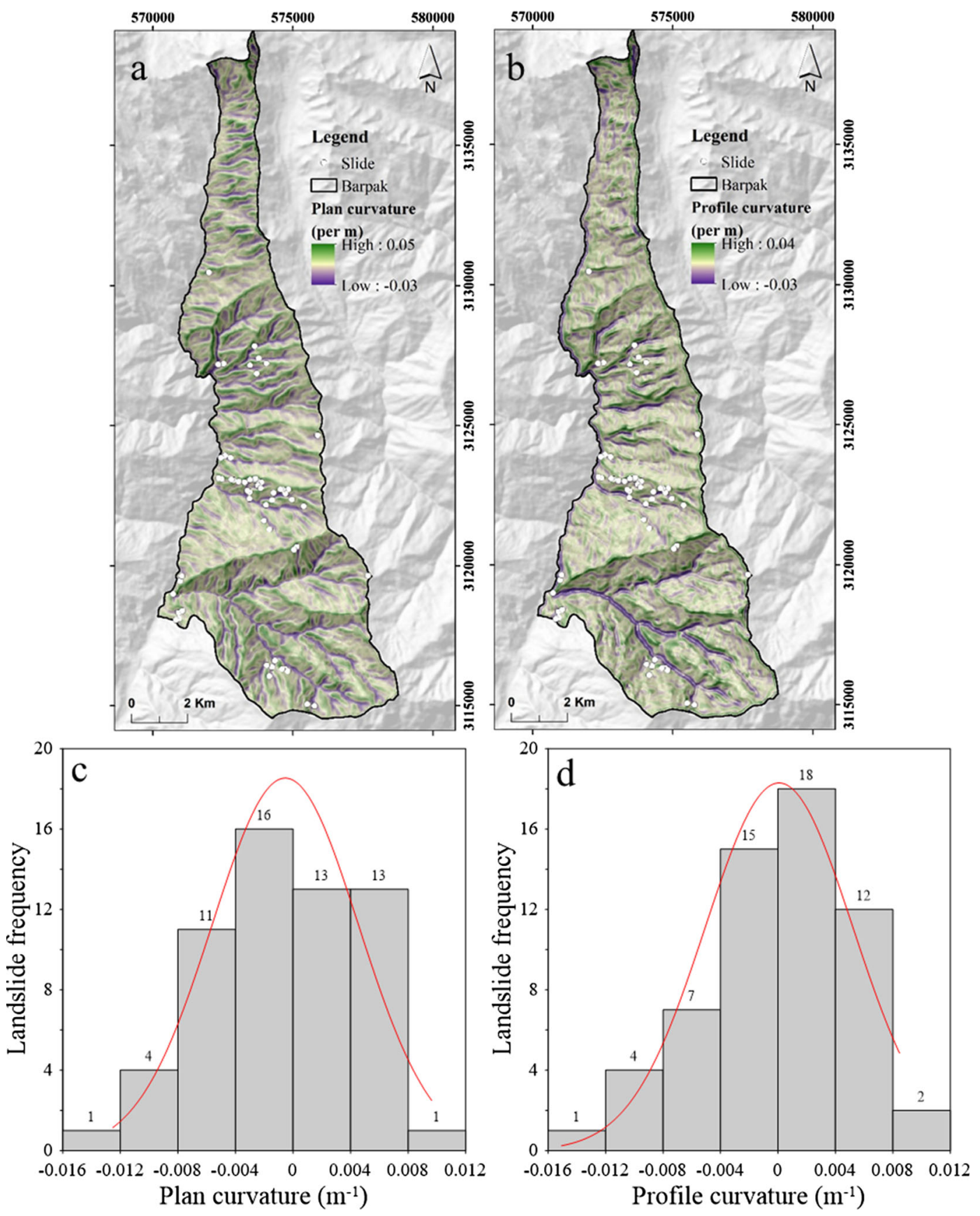

Figure 11. (a) Plan curvature; (b) profile curvature; (c) distribution in profile curvature.

(c) landslide distribution in plan curvature and (d) landslide

associated with the lower order drainage channel which is always vulnerable to instability.

Similarly, by combining the length and steepness of slope, STI (figure 14a) was calculated. It characterizes erosion and the deposition process (Pradhan et al. 2016). The combined slope factor (LS) can be calculated using equation (2), as proposed by Moore and Burch (1986)

$$
\mathrm{LS}=\left(\frac{A_{s}}{22.13}\right)^{0.6}\left(\frac{\sin \beta}{0.0896}\right)^{1.3}
$$

where $A_{s}$ is the specific catchment area and $\beta$ is the local slope gradient measured in degrees.

In the case of landslide distribution in STI, most of the landslides are concentrated within STI values 8-20 (figure 14b), because less value gives less erosion.

\section{Analytical approaches}

In the study area, two statistical approaches were applied and compared to make a final co-seismic 

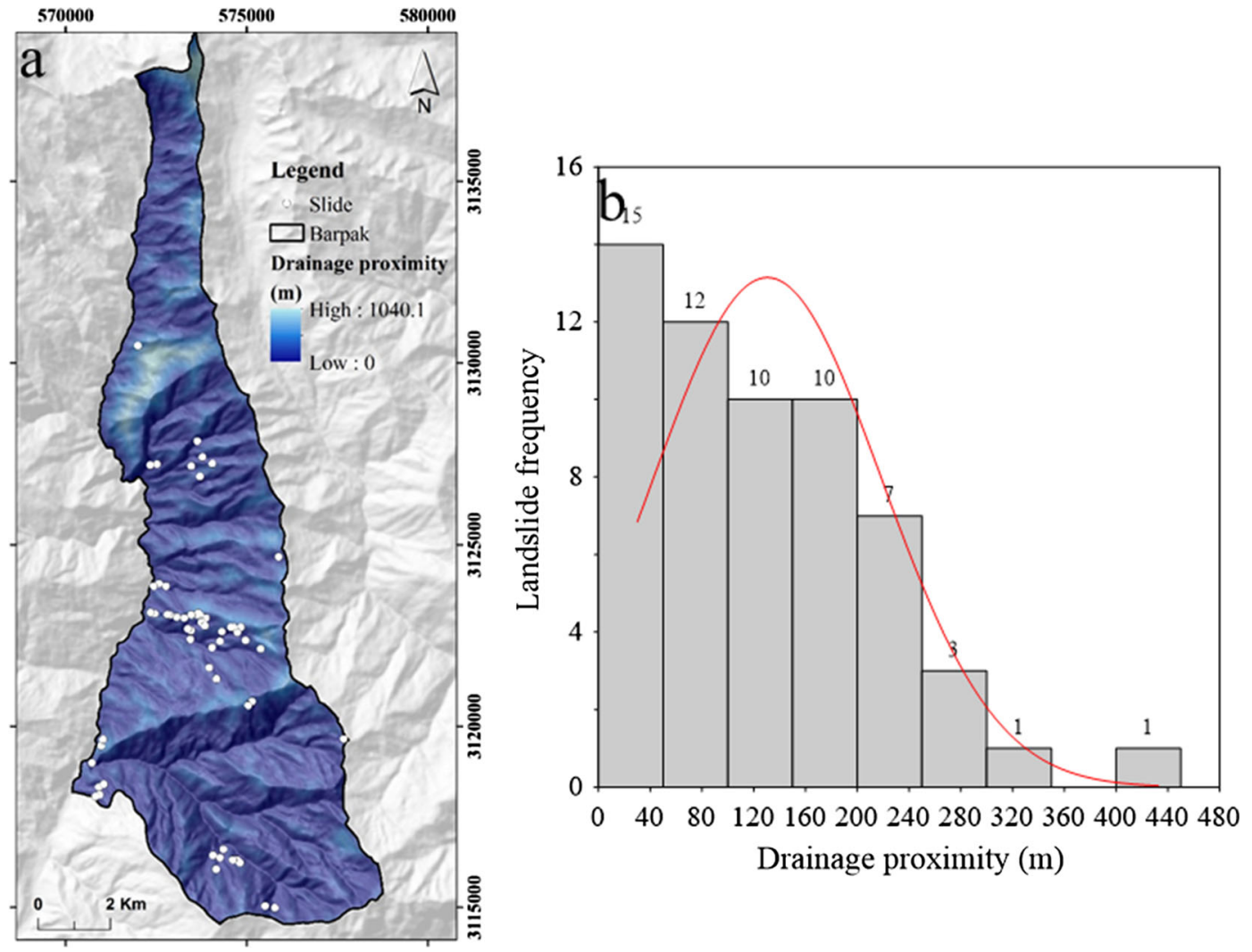

Figure 12. (a) Drainage proximity and (b) landslide distribution.
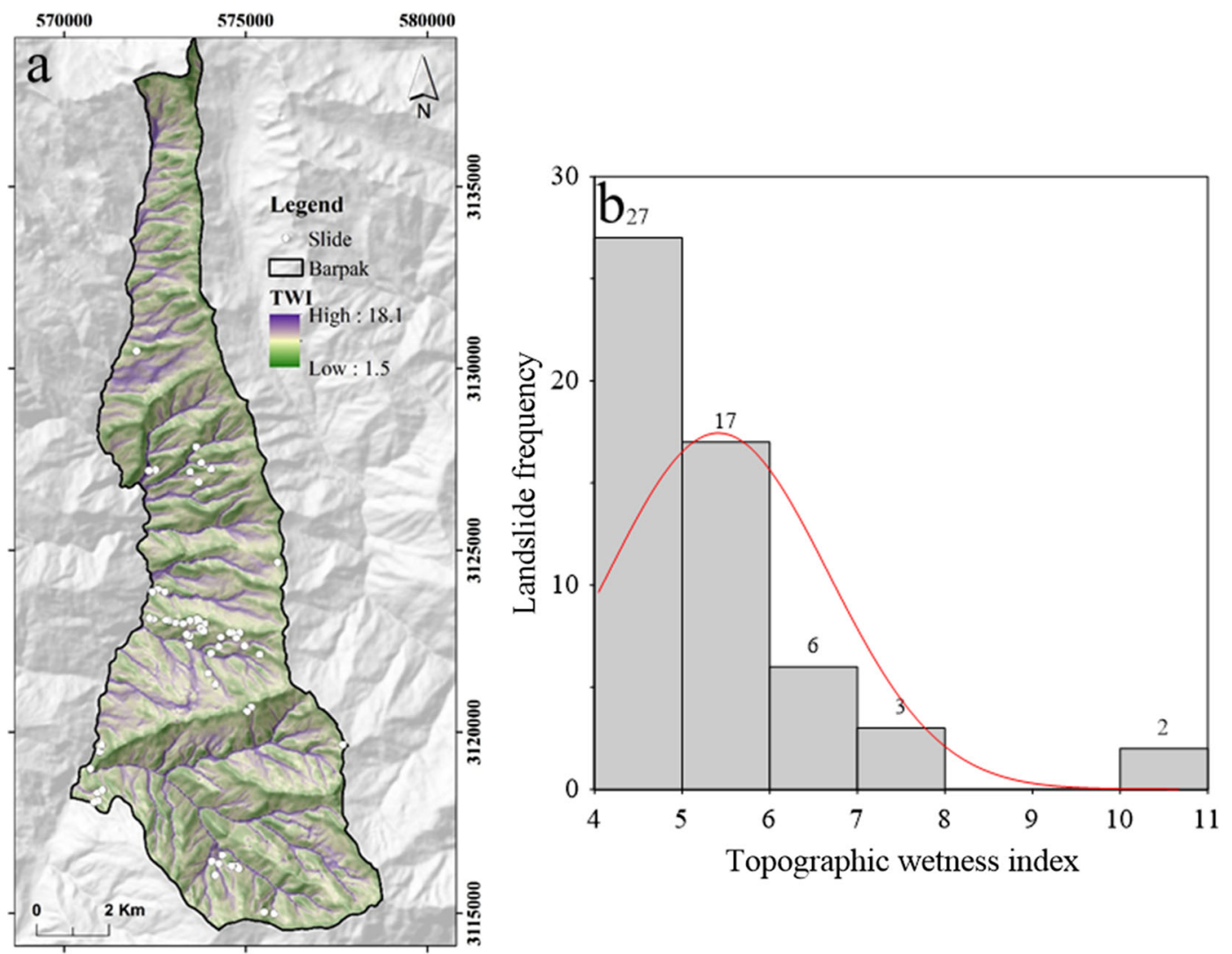

Figure 13. (a) TWI and (b) landslide distribution. 


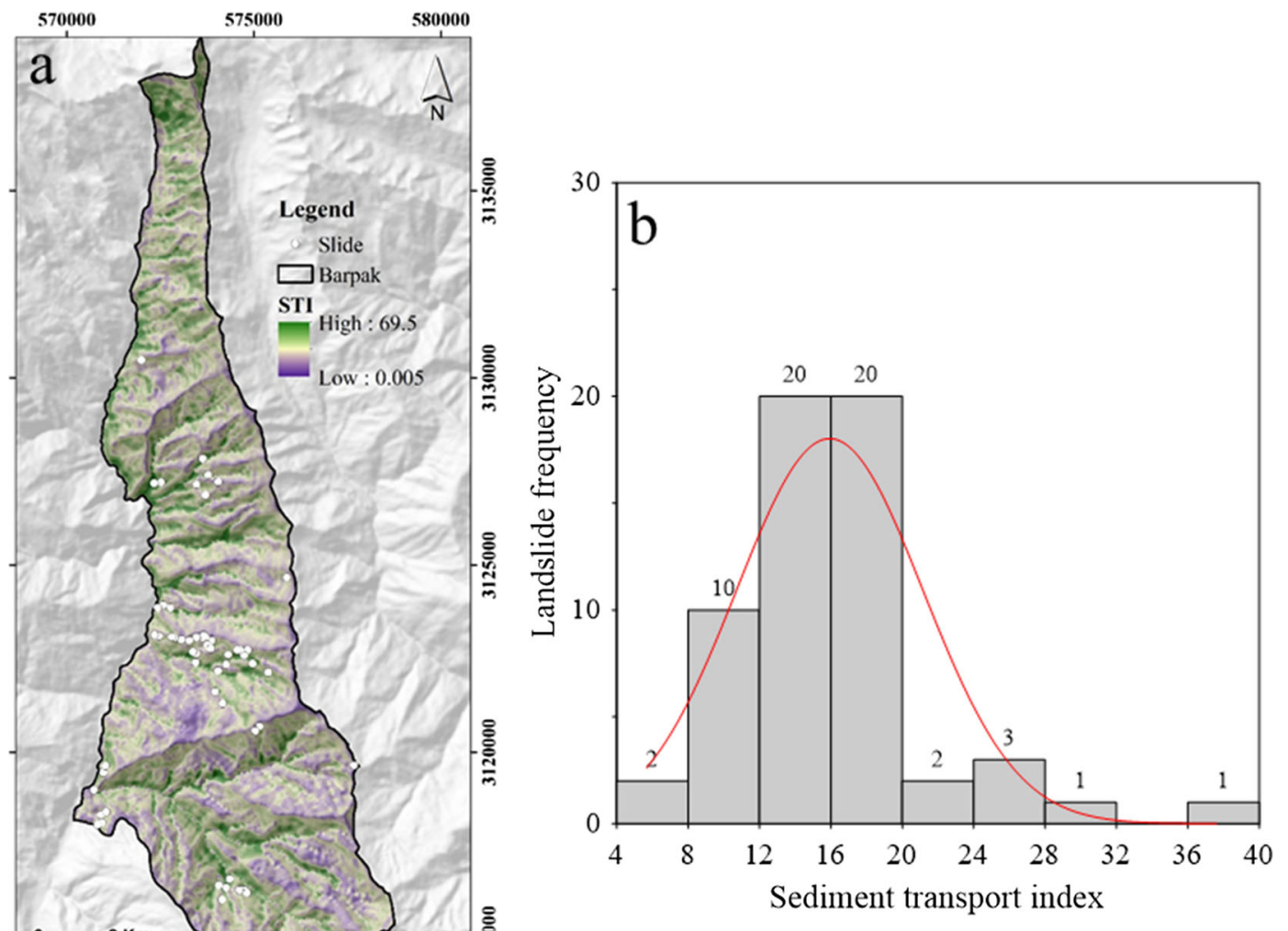

Figure 14. (a) STI and (b) landslide distribution.

landslide susceptibility map. The identified landslide inventory map was used as a dependent variable and $11 \mathrm{CFs}$ were treated as independent variables. Among the $11 \mathrm{CFs}$, only geology is a categorical variable, while the remaining independent variables are continuous variables. Figure 15 shows the procedure applied in the present study.

\subsection{Logistic regression}

Logistic Regression (LR) is an extension of multiple regressions where the dependent variable is not a continuous or quantitative variable (George and Mallery 2000). According to Pradhan and Kim (2015), LR is used to investigate a binary response from a set of measurements using the forward method. Logistic regression can analyze predictor variables to predict the success or failure of a process based on a set of measurements of all types such as continuous, discrete and dichotomous, and can also produce a nonlinear model (Mertler and Reinhart 2016). These variables do not necessarily have normal distributions. A logarithmic model relationship is used instead of a linear relationship between the independent variables and the response. The dependent variable is a binary variable which represents the presence or absence of a landslide and has a value of either 0 or 1 , hence the model applies well to the landslide susceptibility analysis. To estimate the ratios for each of the independent variables in the model, the LR can be used. Such relationships between the occurrence and its dependency on various variables can be expressed in equation (3)

$$
p=\frac{1}{1+e^{-z}},
$$

where $p$ gives the probability of landslide occurrence, which ranges from 0 and 1 , and $z$ is a linear combination of the variables through equation (4)

$$
z=b_{0}+b_{1} x_{1}+b_{2} x_{2}+\cdots+b_{n} x_{n},
$$

where $b_{0}$ is the intercept of the model, $b_{1}, b_{2}, \ldots, b_{n}$ are the slope coefficients of the LR model, and $x_{1}, x_{2}, \ldots, x_{n}$ are the independent variables.

\subsection{Analysis of covariance}

Covariance analysis (ANCOVA) is a general linear model that evaluates whether the average of the 


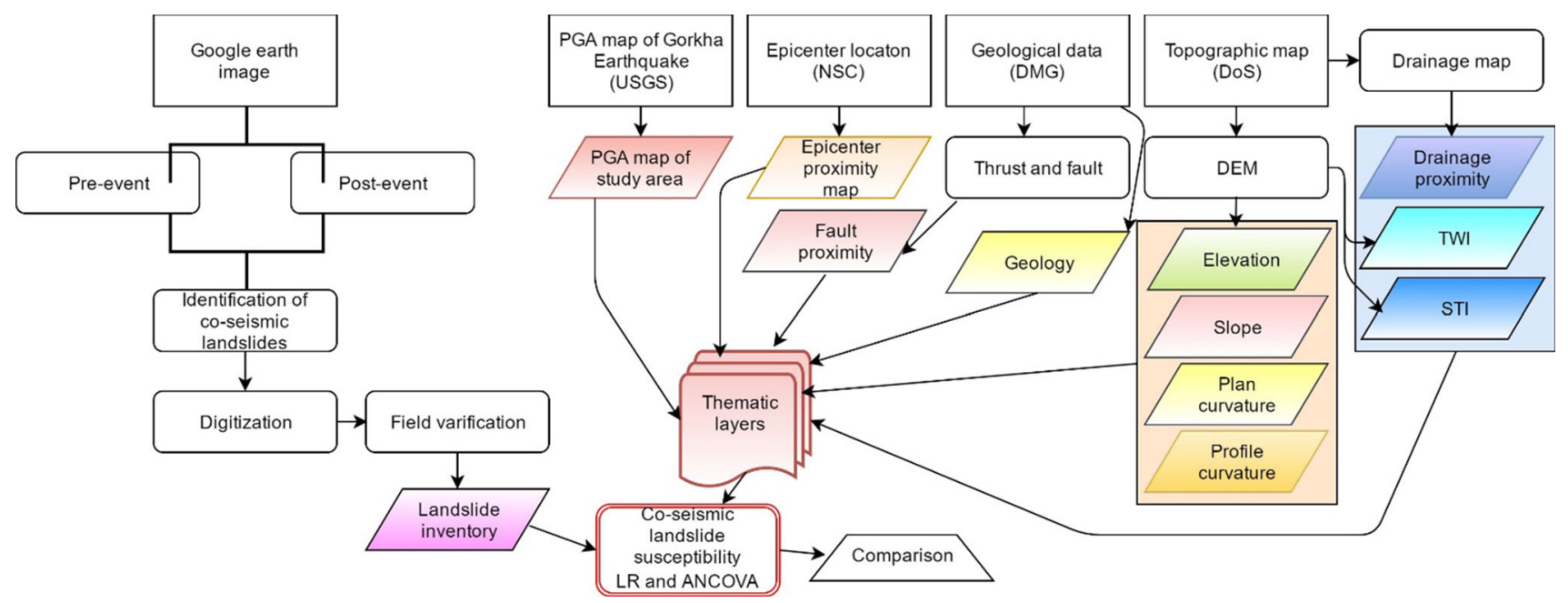

Figure 15. Procedure applied in the present study.

population of the dependent variable is equal to the level of a categorical independent where covariates are not interested. ANCOVA can be regarded as 'adapting' the dependent variable by the group means of the independent variables (Leech et al. 2005). In general, while removing the effect of the covariate factor, ANCOVA test the effect of an independent variable on a dependent variable.

If $q$ is the number of CFs and $p$ is the number of quantitative variables, then the ANCOVA model can be written as

$$
\begin{aligned}
z= & b_{0}+\sum j=1 \ldots p b_{j} x_{i j} \\
& +\sum j=1 \ldots q b k(i, j), j+\varepsilon_{i},
\end{aligned}
$$

where $z$ is the value detected for the dependent variable for observation $i, x_{i j}$ is the value used by quantitative variable $j$ for observation $i, k(i, j)$ is the index of the group of factor $j$ for observation $i$ and $\varepsilon_{i}$ is the error of the model.

\section{Results and discussion}

To process the available input data layers, all the CFs, landslide and non-landslide data were converted to point data in a GIS environment. All the values of CFs were assigned to landslide (value 1) and non-landslide (value 0) point data and exported as a table in GIS. Then, the binary LR and ANCOVA analysis were performed using XLSTAT (Trial version), a statistical package for Microsoft excel. From there, the $b$ coefficient and intercept for numerical and categorical data were obtained.
Table 1 shows the $b$ coefficient of each conditioning factors for the LR and ANCOVA. It is observed that PGA $(b=19.37)$, profile curvature $(b=53.2)$, slope $(b=0.075)$ and STI $(b=0.09)$ play a vital role in the landslide susceptibility mapping of the research area. The CFs epicenter proximity, fault proximity, plan curvature and TWI have negative $b$ values. Here the negative value means that when the value of CFs increases, the probability of a landslide decreases, i.e., an inverse effect on landslide susceptibility.

In the LR analysis, the significance of chi-square is larger than 0.05 (table 2), which means the goodness-of-fit of the equation can be accepted according to the Hosmer and Lemeshow test (Hosmer and Lemeshow 2000). During this analysis, a confidence interval was selected as $95 \%$ and iterations were 100 . Then, for maximum of the likelihood function, the Newton-Raphson algorithm was used.

One of the most important steps in the ANCOVA model is the analysis of the relationship between dependent variables or the multi-collinearity test. A multi-collinearity test was done on the set of 11 $\mathrm{CFs}$ to reduce the dimension of CFs. The variance inflation factor (VIF) and tolerance (TL) are widely used indices of the degree of multicollinearity (Kavzoglu et al. 2014; Dou et al. 2015). O'brien (2007) stated that a VIF > 10 and TL of $<0.10$ represent a multi-collinearity problem. According to table 3, no collinearity between independent CFs was observed in the present study. The highest VIF and the smallest TL were 6.04 and 0.1654 , respectively. 
Table 1. $b$ coefficients of the CFs used in LR and ANCOVA.

\begin{tabular}{llcc}
\hline & Conditioning factors & LR & ANCOVA \\
\hline Seismic & PGA & 19.37 & 0.0459 \\
& Epicenter proximity & -0.0004 & $-3.11414 E-6$ \\
& Fault proximity & -0.0001 & $-1.56096 E-6$ \\
Geology & Cr & 0 & 0.0128 \\
& Gp & 0.43 & 0.0168 \\
\multirow{5}{*}{ Topographic } & Hm & -0.9 & 0 \\
& Elevation & $7.35651 E-6$ & $4.86860 E-7$ \\
& Slope & 0.07506 & 0.00070 \\
& Plan curvature & -86.21209 & -0.46061 \\
& Profile curvature & 53.2018 & 0.31553 \\
Hydrologic & Drainage proximity & -0.0007 & $-2.53430 E-6$ \\
& Topographic wetness index & -0.52 & -0.00111 \\
& Sediment transport index & 0.0936 & 0.00008 \\
& Intercept & -18.37 & 0.028 \\
\hline
\end{tabular}

Table 2. Hosmer-Lemeshow test.

\begin{tabular}{lcc}
\hline Statistic & Chi-square & $\operatorname{Pr}>\mathrm{Chi}^{2}$ \\
\hline $\begin{array}{l}\text { Hosmer-Lemeshow } \\
\text { statistic }\end{array}$ & 9.92 & 0.2707 \\
\hline
\end{tabular}

Table 3. The multi-collinearity test for independent CFs in ANCOVA analysis.

\begin{tabular}{lcc}
\hline Statistic & Tolerance & VIF \\
\hline PGA & 0.1793 & 5.5785 \\
Epi prox & 0.4670 & 2.1413 \\
Fault prox & 0.1784 & 5.6055 \\
Cr & 0.8513 & 1.1746 \\
Gp & 0.5390 & 1.8553 \\
Hm & 0.3375 & 2.9633 \\
Elevation & 0.2357 & 4.2427 \\
Slope & 0.1654 & 6.0445 \\
Plan curv & 0.3813 & 2.6229 \\
Profile curv & 0.6823 & 1.4657 \\
Drain prox & 0.7589 & 1.3177 \\
TWI & 0.2115 & 4.7291 \\
STI & 0.1701 & 5.8792 \\
\hline
\end{tabular}

The results of $b$ value for ANCOVA were summarized in table 1. PGA, elevation, slope profile curvature, STI, $\mathrm{Cr}$ and $\mathrm{Hm}$ have a positive correlation of landslide occurrence. In contrast, epicenter proximity, fault proximity, plan curvature and drainage proximity have a negative correlation.

After an analysis of the results, co-seismic landslide susceptibility maps were prepared based on achieved coefficients in table 1 . Thus, the obtained landslide susceptibility maps were classified as very low (VL), low (L), moderate $(\mathrm{M})$, high $(\mathrm{H})$ and very high $(\mathrm{VH})$ as presented in figure 16(a and b). To classify the landslide susceptibility maps, a natural break classification method was used (Mahalingam et al. 2016; Pradhan et al. 2017). The natural break classification method is a data-clustering method designed to determine the best arrangement of values into different classes (Jenks 1967). The features are divided into classes whose boundaries are set where there are relatively big jumps in the data values. In the case of the LR model, the area distribution analysis shows that the percentage of the terrain area with classes of very low (VL), low $(\mathrm{L})$, and moderate $(\mathrm{M})$ is $75.9,17.8$ and $4.4 \%$, whereas these are equal to 1.5 and $0.4 \%$ of high $(\mathrm{H})$ and very high $(\mathrm{VH})$ classes, respectively. LR comes from the fact that ANCOVA can also be used to perform classification problem, but the logistic regression is not linear because it involves a transformation with both an exponential function of $\mathrm{x}$ and a ratio. It is tempting to use the ANCOVA output as probabilities, but it is a mistake because the output can be negative and greater than 1 whereas probability cannot. To overcome this situation, the final value of ANCOVA was rescaled in the range of 0 to 1 using the Max-Min normalization procedure. Thus obtained $0-1$ range was reclassified using natural break algorithm. It was found that 8.1, $19.1,29.7 \%$ areas are flagged as VL, L and M, whereas the $29.8 \%$ area was identified as $\mathrm{H}$ and the remaining $13.3 \%$ area was classified as a VH susceptible area. 

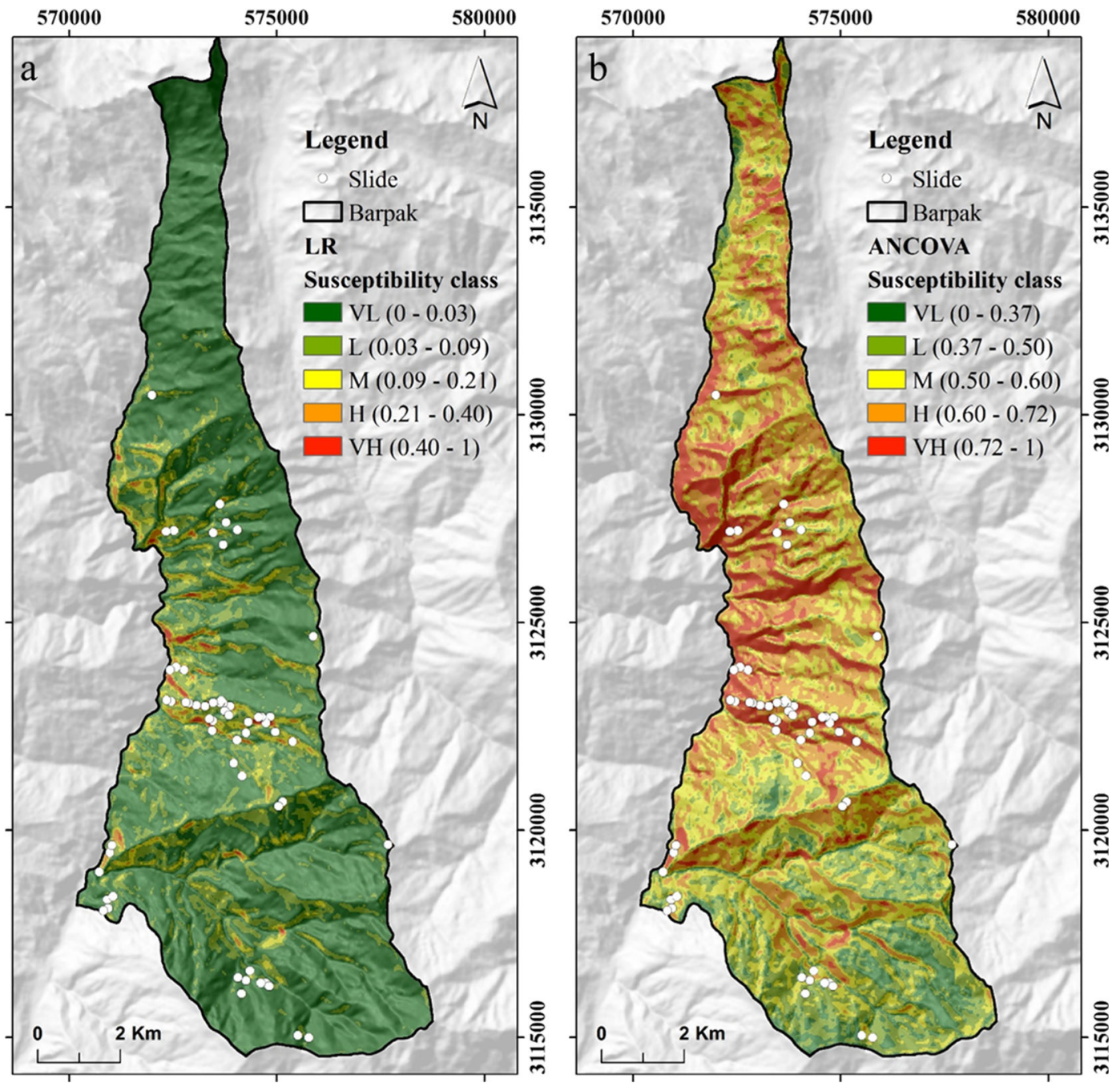

Figure 16. Landslide susceptibility: (a) LR method and (b) ANCOVA method.

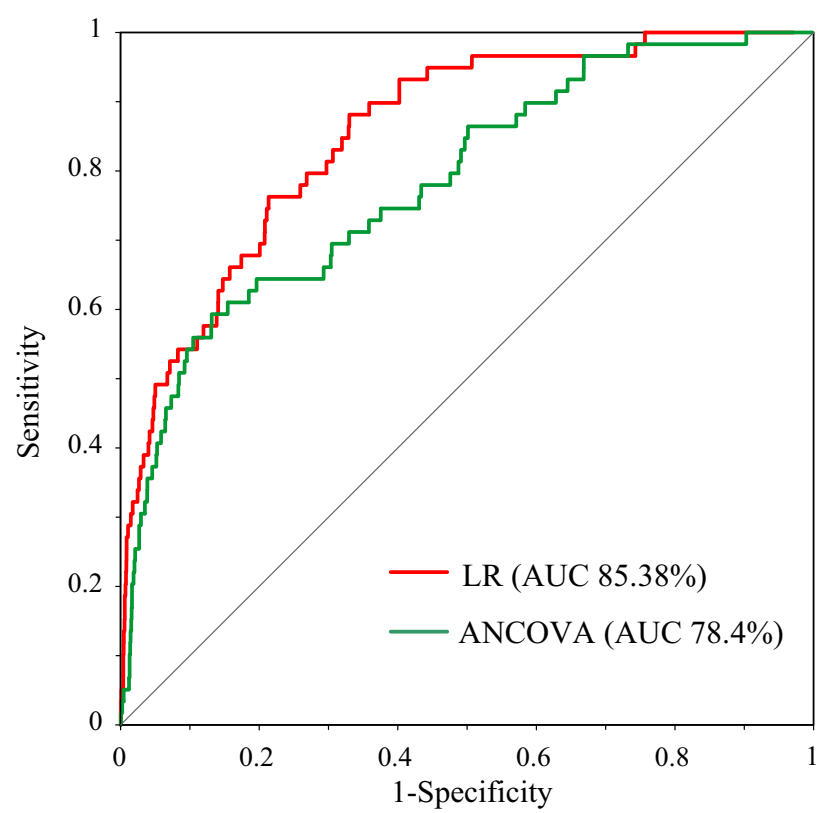

Figure 17. Accuracy assessment using ROC curves.

\section{Model accuracy assessment}

Model performance was assessed using a receiver operating curve (ROC). In order to test the model performance, the ROC is used in a different field. The ROC is an effective tool to represent the character of a forecast system (Swets 1988). The area under the curve (AUC) is used as the indicator for validating the prediction performance of the model (Hanley and McNeil 1982). In this study, the performance capabilities of two sets of results, namely LR and ANCOVA, were evaluated and compared using the AUC. In this process, the landslide inventory map was overlaid with the maps of the final susceptibility in order to count the number of pixels with and without landslides. It is viable to obtain various contingency tables which correspond to various points on the ROC curve by changing the value of the cut-off. The ROC was calculated by plotting the fraction of positive outcomes that were 
correctly identified versus the fraction of positive outcomes that were not correctly identified. The AUC of the susceptibility map obtained from the LR was $85.38 \%$. The accuracy of the susceptibility map obtained from ANCOVA was $78.4 \%$, as shown in figure 17 . Thus, these results show that the susceptibility model with LR is more accurate for predicting landslide events.

\section{Conclusions}

Two co-seismic landslide susceptibility models, using logistic regression (LR) and analysis of covariance (ANCOVA) have been applied in Barpak village. The village was affected by the main shock of the Gorkha earthquake and several aftershocks. The slope failures were induced during this catastrophic earthquake event. For the landslide susceptibility model, 59 landslides were identified and considered as the dependent variable, whereas 11 conditioning factors, namely PGA, epicenter proximity, fault proximity, geology, slope, elevation, plan curvature, profile curvature, topographic wetness index, drainage proximity and the sediment transport index were selected as independent variables. The $b$ values of both models showed that the PGA has positive correlation indicating that the vicinity of the main shock suffered from seismic induced landslides. The obtained landslide susceptibility maps were classified as VL, L, M, $\mathrm{H}$ and $\mathrm{VH}$ using a natural break algorithm. Only $0.4 \%$ of the terrain area was identified as a $\mathrm{VH}$ susceptible area in the LR model, whereas in the ANCOVA model, the VH is $13.3 \%$. The ROC was used for model assessment. It shows that the AUC of the susceptibility map obtained from the LR was $85.38 \%$. The accuracy of the susceptibility map obtained from ANCOVA was 78.4\%. The achieved results showed that the LR model performed better than the ANCOVA approach.

\section{Acknowledgement}

This work was supported by a Research Grant of Pukyong National University (in the year 2016).

\section{References}

Beven K J and Kirkby M J 1979 A physically based, variable contributing area model of basin hydrology/Un modèle à base physique de zone d'appel variable del'hydrologie du bassin versant; Hydrol. Sci. J. 24(1) 43-69.
Bednarik M, Magulová B, Matys M and Marschalko M 2010 Landslide susceptibility assessment of the Kra_ovanyLiptovský Mikuláš railway case study; Phys. Chem. Earth Parts $A / B / C$ 35(3) 162-171.

Bray J D, Rathje E M, Augello A J and Merry S M 1998 Simplified seismic design procedure for lined solid-waste landfills; Geosynthet. Int. 5(1-2) 203-235.

Chung C J F and Fabbri A G 1999 Probabilistic prediction models for landslide hazard mapping; Photogramm. Eng. Rem. Sens. 65(12) 1389-1399.

Dai F C, Lee C F, Li J and Xu Z W 2001 Assessment of landslide susceptibility on the natural terrain of Lantau Island, Hong Kong; Environ. Geol. 40(3) 381-391.

Delgado J, Garrido J, López-Casado C, Martino S and Peláez J A 2011 On far field occurrence of seismically induced landslides; Eng. Geol. 123(3) 204-213.

Devkota K C, Regmi A D, Pourghasemi H R, Yoshida K, Pradhan B, Ryu I C, Dhital M R and Althuwaynee O F 2013 Landslide susceptibility mapping using certainty factor, index of entropy and logistic regression models in GIS and their comparison at Mugling-Narayanghat road section in Nepal Himalaya; Nat. Hazards 65(1) 135-165.

Dewey J F and Burke K C 1973 Tibetan, Variscan and Precambrian basement reactivation: Products of continental collision; J. Geol. 81(6) 683-692.

Dou J, Bui D T, Yunus A P, Jia K, Song X, Revhaug I, Xia H and Zhu Z 2015 Optimization of causative factors for landslide susceptibility evaluation using remote sensing and GIS data in parts of Niigata, Japan; PLoS One 10:e0133262, https://doi.org/10.1371/journal.pone. 0133262.

Ercanoglu M, Gokceoglu C and Van Asch T W 2004 Landslide susceptibility zoning north of Yenice (NW Turkey) by multivariate statistical techniques; Nat. Hazards $\mathbf{3 2 ( 1 )}$ $1-23$.

George D and Mallery P 2000 SPSS for Windows: A simple guide and reference; Allyn \& Bacon, Boston, MA.

Gökceoglu C and Aksoy H 1996 Landslide susceptibility mapping of the slopes in the residual soils of the Mengen region (Turkey) by deterministic stability analyses and image processing techniques; Eng. Geol. 44(1-4) 147161.

Hanley J A and McNeil B J 1982 The meaning and use of the area under a receiver operating characteristic (ROC) curve; Radiology 143(1) 29-36.

Harp E L, Jibson RW, Kayen R E, Keefer D K, Sherrod B L, Carver G A, Collins B D, Moss R E S and Sitar N 2003 Landslides and liquefaction triggered by the M 7.9 Denali fault earthquake of 3 November 2002; GSA Today 13(8) $4-10$.

Hosmer D W and Lemeshow S 2000 Interpretation of the fitted logistic regression model. Appl. Logistic Regression; 2nd edn, pp. 47-90.

Jade S and Sarkar S 1993 Statistical model for slope instability classifications; Eng. Geol. 36 71-98.

Jenks G 1967 The data model concept in statistical mapping; Int. Yearb. Cart. 7 347-356.

Jibson R W, Harp E L and Michael J A 2000 A method for producing digital probabilistic seismic landslide hazard maps; Eng. Geol. 58(3) 271-289.

Kamp U, Growley B J, Khattak G A and Owen L A 2008 GIS-based landslide susceptibility mapping for the 
2005 Kashmir earthquake region; Geomorphology 101(4) 631-642.

Kargel J S, Leonard J, Shugar D H, Haritashya U K, Bevington A, Fielding E J, Fujita K, Geertsema M, Miles E S, Steiner J and Anderson E 2016 Geomorphic and geologic controls of geohazards induced by Nepal's 2015 Gorkha earthquake; Science 351(6269) 1-18, 17, https://doi. org/10.1126/science.aac8353.

Kavzoglu T, Sahin E K and Colkesen I 2014 Landslide susceptibility mapping using GIS-based multi-criteria decision analysis, support vector machines, and logistic regression; Landslides 11(3) 425-439.

Keefer D K 1994 The importance of earthquake-induced landslides to long-term slope erosion and slope-failure hazards in seismically active regions; Geomorphology 10(14) $265-284$.

Kritikos T, Robinson T R and Davies T R 2015 Regional coseismic landslide hazard assessment without historical landslide inventories: A new approach; J. Geophys. Res. Earth Surface 120(4) 711-729.

Lee C T, Huang C C, Lee J F, Pan K L, Lin M L and Dong J J 2008 Statistical approach to earthquake-induced landslide susceptibility; Eng. Geol. 100(1) 43-58.

Lee S and Evangelista D G 2006 Earthquake-induced landslide-susceptibility mapping using an artificial neural network; Nat. Hazard Earth Syst. 6(5) 687-695.

Leech N L, Barrett K C and Morgan G A 2005 SPSS for intermediate statistics: Use and interpretation; Psychology Press.

Liao H W and Lee C T 2000 Landslides triggered by the Chi-Chi earthquake; In: Proceedings of the 21st Asian Conference on Remote Sensing, Taipei, pp. 1-2.

Magliulo P, Di L A, Russo F and Zelano A 2008 Geomorphology and landslide susceptibility assessment using GIS and bivariate statistics: A case study in southern Italy; Nat. Hazards 47(3) 411-435.

Mahalingam R, Olsen M J and O'Banion M S 2016 Evaluation of landslide susceptibility mapping techniques using lidar-derived conditioning factors (Oregon case study); Geomat. Nat. Hazard Risk 7(6) 1884-1907.

Mertler C A and Reinhart R V 2016 Advanced and multivariate statistical methods: Practical application and interpretation; Routledge.

Miles S B and Keefer D K 2000 Evaluation of seismic slopeperformance models using a regional case study; Environ. Eng. Geosci. 6(1) 25-39.

Miles S B and Keefer D K 2007 Comprehensive areal model of earthquake-induced landslides: Technical specification and user guide; US Geol. Survey.

Miles S B and Keefer D K 2009a Evaluation of CAMEL comprehensive areal model of earthquake-induced landslides; Eng. Geol. 104(1) 1-15.

Miles S B and Keefer D K 2009b Toward a comprehensive areal model of earthquake-induced landslides; Nat. Hazards Rev. 10(1) 19-28.

Moore I D and Burch G J 1986 Physical basis of the lengthslope factor in the universal soil loss equation; Soil Sci. Soc. Am J. 50(5) 1294-1298.

Moore I D, Grayson R B and Ladson A R 1991 Digital terrain modelling: A review of hydrological, geomorphological, and biological applications; Hydrol. Process. 5 (3-30).
Newmark 1965 Effects of earthquakes on dams and embankments; Geotechnique 15(1965) 139-159.

O'brien R M 2007 A caution regarding rules of thumb for variance inflation factors; Quality \& Quantity 41(5) 673690.

Pradhan A M S and Kim Y T 2015 Application and comparison of shallow landslide susceptibility models in weathered granite soil under extreme rainfall events; Environ. Earth Sci. 73(9) 5761-5771.

Pradhan A M S, Kang H S, Lee S and Kim Y T 2016 Spatial model integration for shallow landslide susceptibility and its runout using a GIS-based approach in Yongin, Korea; Geocarto. Int. 32(4) 420-441.

Pradhan A M S and Kim Y T 2016 Evaluation of a combined spatial multi-criteria evaluation model and deterministic model for landslide susceptibility mapping; Catena 140 125-139.

Pradhan A M S, Kang H S Lee S and Kim Y T 2017 Spatial model integration for shallow landslide susceptibility and its runout using a GIS-based approach in Yongin, Korea; Geocarto Int. 32(4) 420-441.

Pradhan B and Lee S 2010 Landslide susceptibility assessment and factor effect analysis: Back propagation artificial neural networks and their comparison with frequency ratio and bivariate logistic regression modelling; Environ. Modell. Softw. 25 747-759.

Regmi A D, Dhital M R, Zhang J Q, Su L J and Chen X Q 2016 Landslide susceptibility assessment of the region affected by the 25 April 2015 Gorkha earthquake of Nepal; J. Mt. Sci. 13(11) 1941-1957.

Regmi N R, Giardino J R and Vitek J D 2010 Modeling susceptibility to landslides using the weight of evidence approach: Western Colorado, USA; Geomorphology 115 172-187.

Reneau S L and Dietrich W E 1987 Size and location of colluvial landslides in a steep forested landscape; IAHSAISH Publ. 165 39-48.

Saputra A, Gomez C, Hadmoko D S and Sartohadi J 2016 Coseismic landslide susceptibility assessment using geographic information system; Geoenviron. Disast. 3(1) 27.

Sarma S K 1975 Seismic stability of earth dams and embankments; Geotechnique 25(4) 743-761.

Seed H B, Lee K L, Idriss I M and Makdisi R 1973 Analysis of the slides in the San Fernando dams during the earthquake of Feb. 9, 1971; Earth Eng. Research Center, University of California, Berkeley; Report No. EERC 73-2, 150p.

Sharma C K 1990 Geology of Nepal Himalaya and Adjacent Countries; Sangeeta Sharma, Kathmandu.

Swets J A 1988 Measuring the accuracy of diagnostic systems; Science 240(4857) 1285.

Wang L J, Guo M, Sawada K, Lin J and Zhang J 2015 Landslide susceptibility mapping in Mizunami City, Japan: A comparison between logistic regression, bivariate statistical analysis and multivariate adaptive regression spline models; Catena 135 271-282.

Wasowski J, Keefer D K and Lee C T 2011 Towards the next generation of research on earthquake-induced landslides: current issues and future challenges; Eng. Geol. 122(1) $1-8$.

Weng M C, Wu M H, Ning S K and Jou Y W 2011 Evaluating triggering and causative factors of landslides in 
Lawnon River Basin, Taiwan; Taiwan; Eng. Geol. 123(1) 72-82.

Yegian M K, Marciano E A and Ghahraman V G 1991 Earthquake-induced permanent deformations: probabilistic approach; J. Geotech. Eng. 117(1) 35-50.
Zhou S, Chen G and Fang L 2016 Distribution pattern of landslides triggered by the 2014 Ludian earthquake of China: Implications for regional threshold topography and the seismogenic fault identification; ISPRS Int. J. GeoInf. 5(4) 46.

Corresponding editor: NAVIN JUYAL 